\title{
Waterbike injuries
}

\section{Robert S. Jeffery FRCS and Siân Caiach* FRCS}

Orthopaedic Department, Queen Alexandra Hospital, Portsmouth and *Department of Orthopaedics, Dundee Royal Infirmary, Dundee, UK

\begin{abstract}
Jet skiing is a rapidly growing sport. The craft incorporate safety features and the manufacturers issue detailed safety instructions. Racing is conducted with adequate attention to clothing, safety and insurance. However, casual use is widespread and is sometimes irresponsible. Serious injuries to riders are uncommon: dental and knee injuries are described. A case of renal contusion and a head injury were caused by other riders and two potentially fatal injuries illustrate the risk for other water users. The number of injuries associated with the use of personal watercraft is likely to increase and may be influenced by appropriate organization or regulation.
\end{abstract}

Keywords: Watersports injuries, sports regulations, personal watercraft

The recent popularity of jet skiing has been accompanied by concern about inconsiderate use at some lakes and coastal resorts ${ }^{1}$ (Figure 1).

Different types of personal watercraft have individual operating and handling characteristics. Water is drawn through a grill on the undersurface of the craft, driven through a sealed petrol-driven impeller and expelled as a jet. The rider stands, kneels or sits and controls the speed and direction using handlebars. If the rider falls from the craft it circles at low

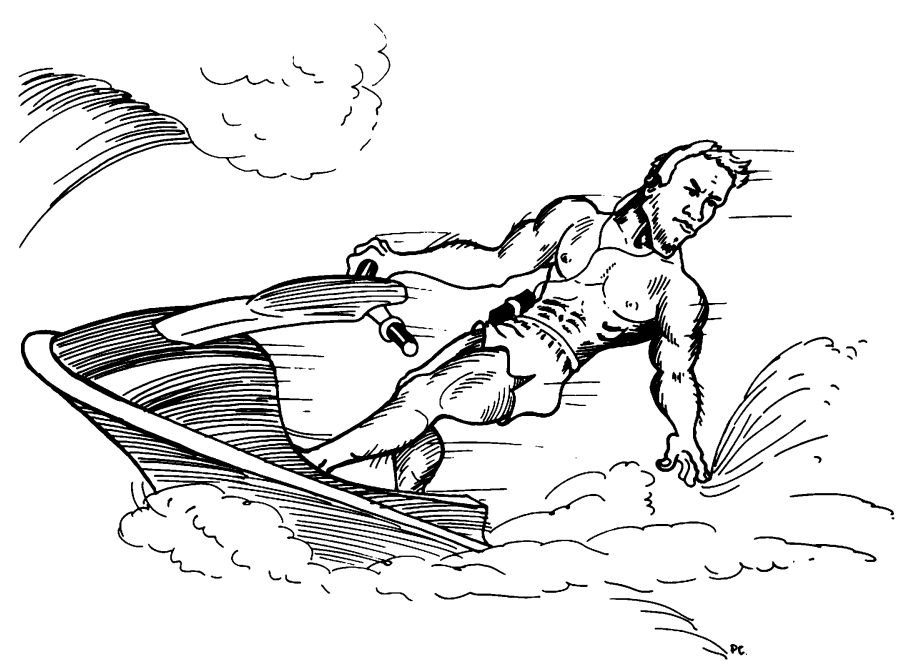

Figure 1. Macho antics bring the sport into disrepute

Address for correspondence: Mr R. S. Jeffery, Kenmore Cottage, The Friary, Old Windsor, Windsor, Berkshire, SL4 2NP, UK

(C) 1991 Butterworth-Heinemann Ltd 0306-3674/91/040232-03 speed. There is a reserve fuel tank and a fire extinguisher compartment. Safety instructions are printed on the machines and included in the handbook. Booklets are issued by sports organizations and many dealers provide introductory lessons.

Racing is usually conducted under conditions dictated by the United Kingdom Jet Ski Association. Helmets, shoes and buoyancy aids are worn; races are attended by paramedical staff and insurance is compulsory. In contrast, casual use is often reckless or irresponsible. There is no compulsory insurance or test in the UK.

Serious injury to the rider is uncommon, but other water users are exposed to greater danger.

\section{Case reports}

\section{Case 1: severe knee injury ${ }^{2}$}

A 42-year-old man was jumping waves a quarter of a mile out to sea when he was thrown from his waterbike. He was uninsured, unaccompanied and wearing no helmet, shoes or buoyancy aid. Not knowing the international distress signal, he waved for help, and passers-by waved back. He managed to drive the machine back to the shore, trailing himself in the water, experiencing great pain in his left knee.

He sustained comminuted fractures of the medial and lateral tibial plateaux, a ruptured medial ligament and a bucket-handle tear of the lateral meniscus, and he avulsed the tibial spines (Figure 2). The knee was surgically reconstructed and he required extensive rehabilitation.

\section{Case 2: dental injuries}

A 21-year-old man fell off his waterbike. There was a cut on his lower lip. The enamel and dentine of the upper central incisors were chipped, and the left second upper tooth was mobile. There were no facial bone or dental root fractures.

\section{Case 3: renal contusion}

A 20-year-old girl was knocked from her waterbike after being caught in the wash of her companion's waterbike. She presented with loin pain and haematuria. She required transfusion of 5 units of blood and laparotomy confirmed the ultrasound findings of contusion of the lower pole of the left kidney with a large adjacent retroperitoneal haematoma. She also had a fracture of the left ilium. 


\section{Case 4: head and facial injury}

A 24-year-old man was struck by another waterbike after he fell off his own. He sustained fractures of the right zygoma, maxillary antrum, condyle of the
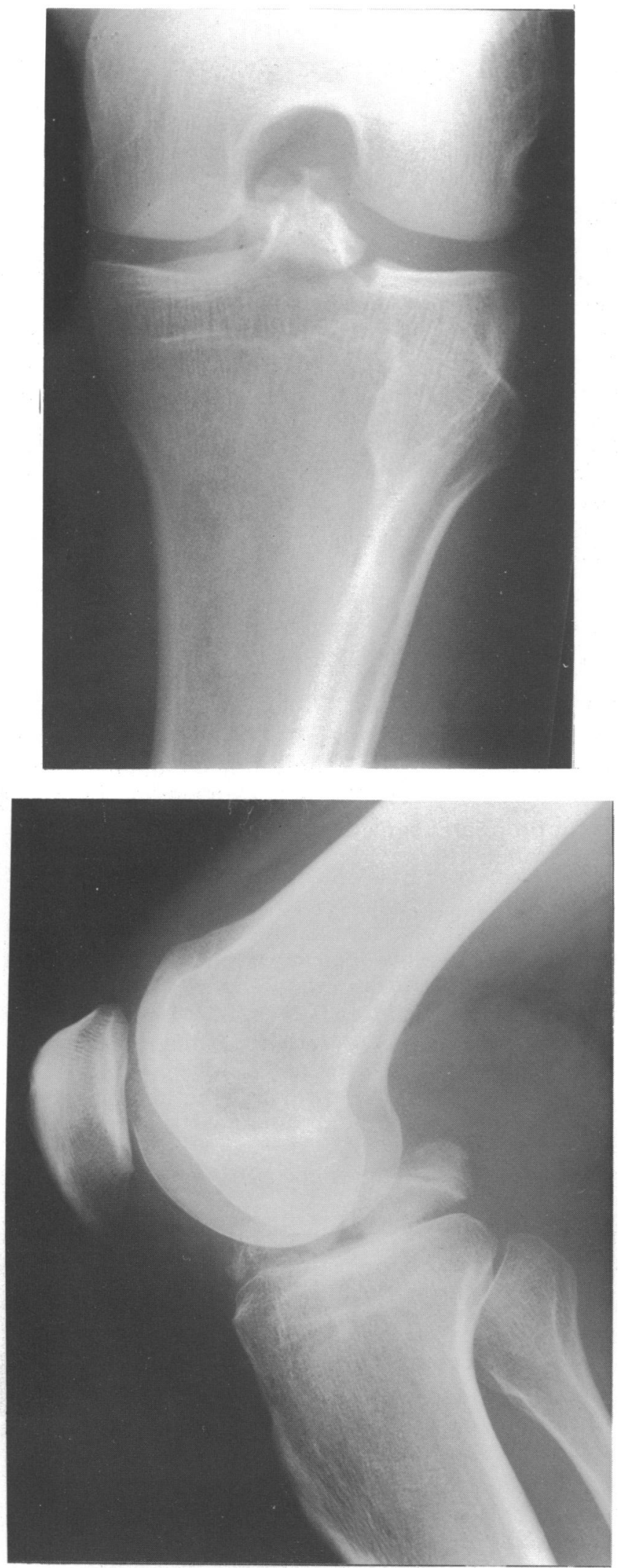

Figure 2. Case 1: severe knee injury. Reproduced by kind permission of the Editor of the British Medical Journal ${ }^{2}$ ) mandible and frontal bone, and a compound fracture of the middle cranial fossa (Figure 3). When his conscious state was stable, his eye swelling had reduced and the cerebrospinal fluid otorrhoea had ceased he underwent reduction and stabilization of the zygoma, orbital floor and mandible.

\section{Case 5: head injury}

A 22-year-old Briton was on holiday in Greece with his girlfriend. They were $150 \mathrm{~m}$ from the shore when their pedalo was struck by a waterbike. The pedalo sank immediately and the man lay unconscious in the water. Fortunately, their companions were able to support him until a boat arrived.

\section{Case 6: multiple injuries}

The 21-year-old girlfriend of case 5 suffered the following injuries: (1) fractures of the left fourth to eighth ribs; (2) rupture and severe contusion of the jejunum, ileum and descending colon; (3) open comminuted fracture of the pelvic ring and left acetabulum (Figure 4), with a degloving injury of the left buttock; and (4) comminuted fracture of the left proximal femur and midshaft fracture of the left tibia and fibula.

The patient developed the adult respiratory distress syndrome after an emergency laparotomy and was transferred to Dundee 12 days after the injury for fixation of her fractures. She was discharged 6 weeks later on crutches.

\section{Discussion}

About 10000 jet skis have been sold in the UK by the leading manufacturer and ten times this number have been sold worldwide. In December 1990, there were 323 UK race licence holders and 15 registered clubs. The injuries reported here were collected by writing to coastal hospitals and appealing for cast in a journal $^{2}$ and, although we do not claim a quantitative survey, the sport would appear to be safer than motorcycling.

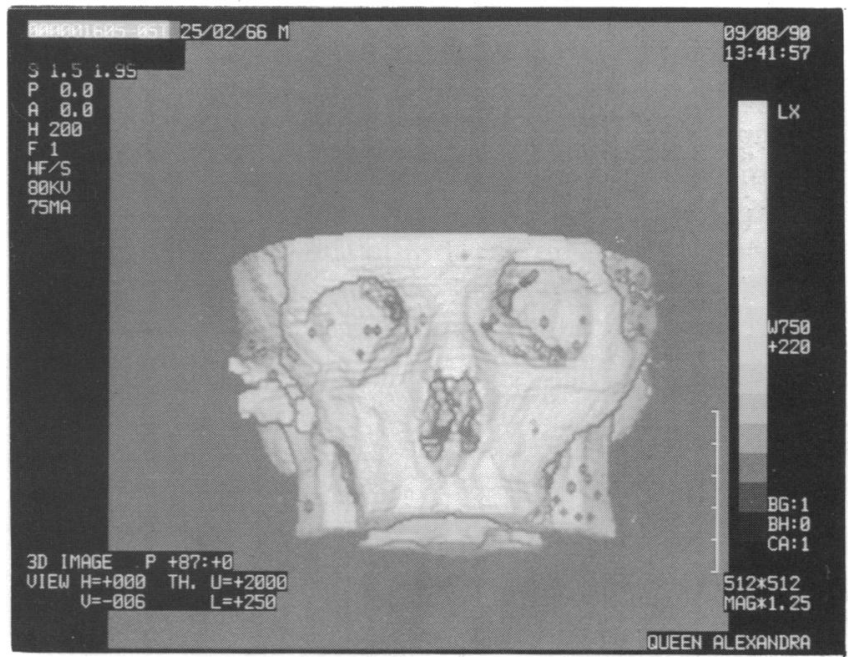

Figure 3. Case 4: CT reconstruction of head and facial injuries 


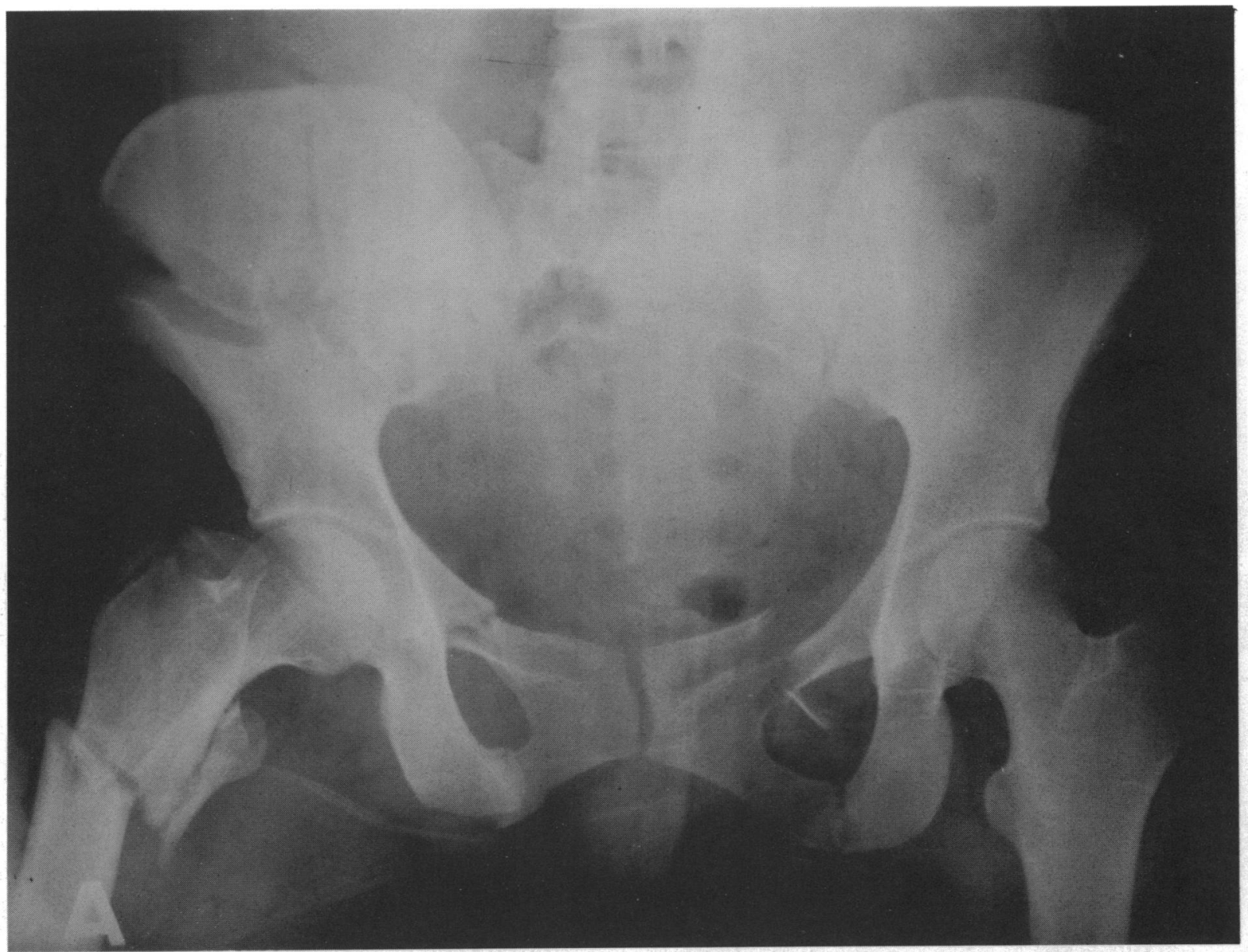

Figure 4. Case 6: pelvic and left hip injury

Falling from waterbikes rarely results in injury. Riders may be injured by indirect forces owing to the momentum of the rider or the craft. The sealed impeller avoids the risk of severe propeller injuries ${ }^{3}$. Spray can obscure the vision of the rider and bathers, divers and other boat users may be struck by waterbikes travelling at speed. Injury could lead to exposure, hypothermia or drowning. Open wounds may become infected with marine organisms ${ }^{3}$.

The most suitable distress signals are raising and lowering outstretched arms, waving a garment or using a red flare or orange smoke signal. There are compartments for fire extinguishers and it is compulsory in the USA, but not in the UK, to carry one.

Some people using waterbikes casually do not adhere to the plentiful advice available. We suggest third party insurance should be compulsory. The number of injuries associated with the use of waterbikes is likely to increase and may be influenced by appropriate regulation and, in particular, segregation from bathers.

\section{Acknowledgements}

Case 1 has previously been reported in the Views column of the British Medical Journal ${ }^{2}$. We thank $\mathrm{Mr}$ I. T. A. Jeffery, Mr M. L. Grover, Mr M. S. Turner, Mr A. J. Edge, Mr A. Bird and Dr E. Tilley for help and permission to report the cases. Mr P. Cox MMAA drew the cartoon and we thank the Radiology and Photography Departments.

\section{References}

1 Rowland J. Resorts to rein in jet ski riders. The Sunday Times 18 June 1989, A11.

2 Jeffery R, Caiach S. Severe knee injury jet skiing. Br Med J 1990; 301: 132.

3 Kutarski PW. Outboard motor propeller injuries. Injury 1989; 20: $87-91$. 
with moving from a very sedentary state (maximal oxygen intake $\left(<21 \mathrm{ml} \mathrm{kg}^{-1} \mathrm{~min}^{-1}\right)$ to what is still a sedentary lifestyle $\left(30 \mathrm{ml} \mathrm{kg}^{-1} \mathrm{~min}^{-1}\right)$. Over this range, the relevant issue may be the proportion of body fat or a genetic difference of body build rather than the pattern of personal physical activity, and any causal explanation could not be clearly linked to earlier studies that have shown protection against colonic or reproductive cancer from athletic participation or engagement in a demanding physical occupation. It may be for this reason that Blair et $a .^{3}$ found a stronger association between physical fitness and overall cancer mortality rates than might have been anticipated from some previous studies ${ }^{1,2}$.

\section{References}

1 Shephard RJ. Exercise and malignancy. Sports Med 1986; 3: 235-41.

2 Shephard RJ. Physical activity and cancer. Int J Sports Med 1990; 11: 413-20.

3 Blair SN, Kohl HW, Paffenbarger RW, Clark DG et al. Physical fitness and all-cause mortality. A prospective study of healthy men and women. JAMA 1989; 262: 2395-401.

4 Shephard RJ. Exercise and lifestyle change. $\mathrm{Br} J$ Sports Med 1989; 23: 11-22.

5 Fitness Canada. Fitness and Lifestyle in Canada. Ottawa: Fitness and Lifestyle Research Institute, 1983.

\section{Erratum}

Jeffery RS, Caiach S. Waterbike injuries. Br J Sports Med 1991; 25: 232-4.

The publishers wish to apologise for a printing error which occurred in the above article. Figure 4 was reversed left to right but is shown here in the correct orientation.

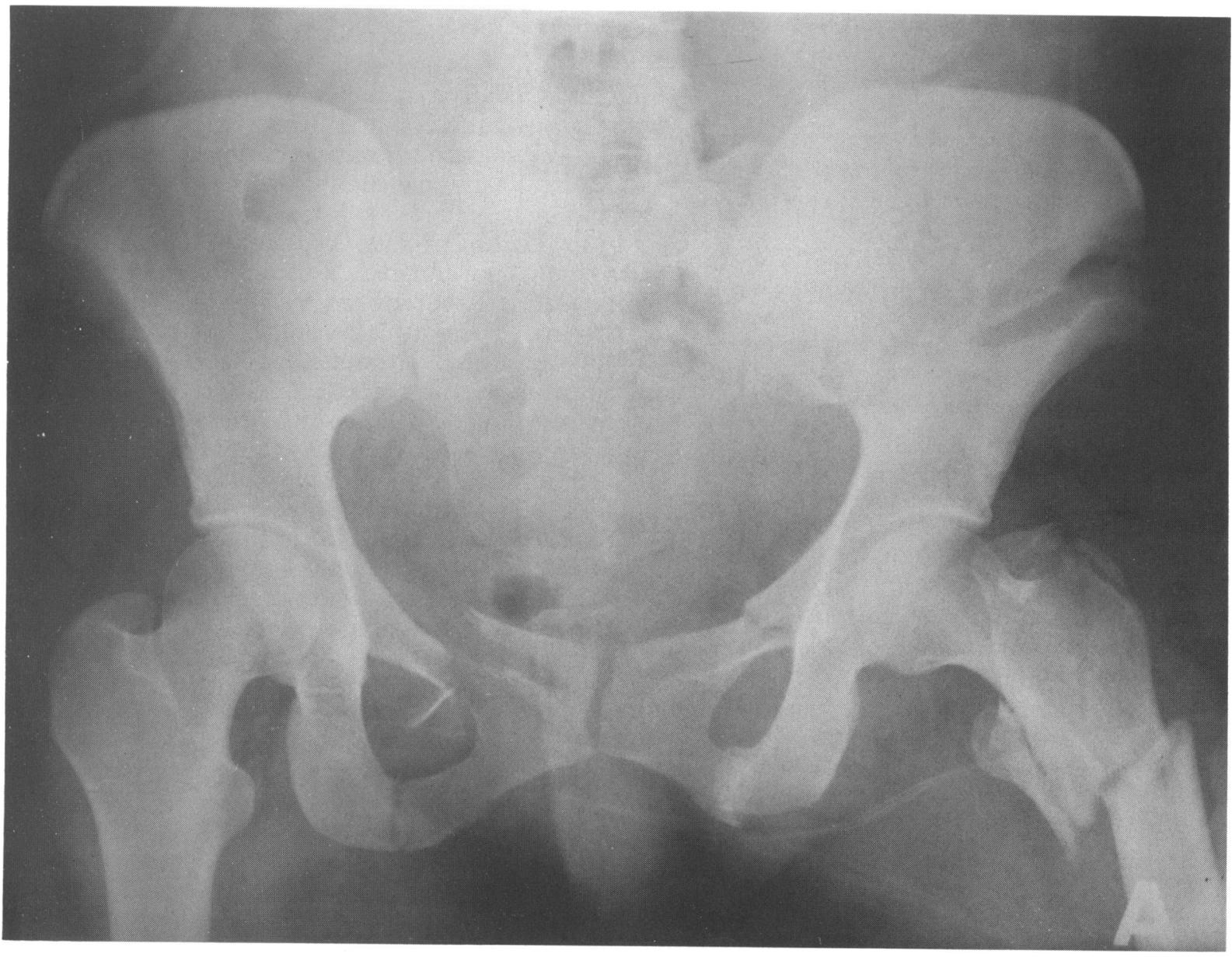

Figure 4. Case 6: pelvic and left hip injury 